\title{
त्री \\ O modelo das interações entre as atividades científicas e os valores
}

\author{
Hugh LAGEY \\ Pablo Rubén MaRiconda
}

\begin{abstract}
茴
RESUMO

Neste artigo, oferecemos formulações padronizadas das principais ideias do modelo das interações entre as atividades científicas e os valores, proposto em anos recentes na revista Scientiae Studia. O modelo trata das várias funções desempenhadas pelos valores - éticos, sociais, políticos, cognitivos (epistêmicos), religiosos etc. - nas atividades científicas e de seu impacto na viabilidade dos ideais (imparcialidade, abrangência, neutralidade, autonomia) da tradição da ciência moderna.
\end{abstract}

PalaVras-chaVe • Atividade científica. Valores. Imparcialidade. Abrangência. Neutralidade.

Autonomia. Epistemologia. Ética. Política científica.

\section{INTRODUÇÃO: A FUNÇÃO DOS VALORES NA TRADIÇÃO DA GIÊNGIA MODERNA}

A ciência é uma prática social histórica. Isso significa, por um lado, que as atividades científicas de pesquisa, desenvolvimento e avaliação de teorias e exploração das possibilidades da aplicação do conhecimento científico desenvolvem-se no seio de instituições e, por outro lado, que a ciência atualmente institucionalizada representa um estágio da tradição da ciência moderna enraizada em um complexo de valores, composto por certos ideais: imparcialidade, neutralidade, abrangência, autonomia. Sempre há tensão entre os dois lados, entre, de um lado, as atividades de investigação e os produtos obtidos pelos cientistas no interior de instituições reconhecidas como "científicas" e, de outro lado, os valores que mudam com os desdobramentos da tradição e com as flutuações do contexto social das instituições. Contudo, sem a consideração dos valores, faltam critérios para avaliar essas atividades e produtos, motivando (quando apropriado) mudanças e, principalmente, para defender a ciência de ameaças a sua integridade, estima e autoridade.

As atividades científicas não são inteligíveis quando separadas de suas situações sócio-históricas, dos valores incorporados nelas, e dos seus lugares no mundo da vida, isto é, o mundo como encontrado, sentido, com o qual interagimos, descrito em lin- 
guagem, representado e transformado em arte, comunicado e avaliado no curso da vida diária. No mundo da vida, os agentes humanos podem explorar, avaliar e deliberar sobre as possibilidades futuras e contribuir causalmente para quais delas serão realizadas, e (caracteristicamente) as suas ações são explicadas em termos de suas crenças, deliberações, fins, desejos, valores e outros estados intencionais, todos os quais são ininteligíveis quando separados das instituições e dos ecossistemas que são os constituintes principais de suas situações sócio-históricas. Além disso, os objetos do mundo da vida são simultaneamente de vários tipos - objetos físicos, químicos e biológicos, por exemplo, são também objetos ecológicos, sociais, históricos, culturais e econômicos - e eles têm impacto causal em virtude de todos os tipos de coisas que eles são (cf. Lacey, 2009; Ramos, neste número; Sacrini, neste número).

Em anos recentes, no periódico Scientiae Studia tem sido proposto o modelo da interação entre a ciência e os valores (M-CV), que trata das várias funções desempenhadas pelos valores - éticos, sociais, políticos, cognitivos (epistêmicos), religiosos etc. - nas atividades científicas, e do seu impacto na viabilidade dos ideais da tradição da ciência moderna. Neste artigo, ofereceremos formulações padronizadas das principais ideias do M-CV, as quais foram defendidas e detalhadamente apresentadas em outros lugares (cf. Lacey, 2008; 2010). Nos outros artigos deste número de Scientiae Studia (e outros em Estudos Avançados), essas ideias são elaboradas de modo mais completo e demonstramos a relevância do modelo para entender e criticar as práticas e as instituições científicas contemporâneas, no sentido de abrir novas possibilidades de funcionamento dessas instituições.

\section{TeORIAS, ESTRATÉgias E VALORES GOGNITIVOS}

Antes de iniciar a exposição do M-CV, é preciso esclarecer as noções de "teoria", "estratégia" e "valores cognitivos", que são básicas para o entendimento do modelo. Para efeito desta discussão, consideramos que os produtos cognitivos da pesquisa científica (conhecimento e entendimento) são representados em teorias. O M-CV não incorpora uma concepção particular de "teoria (científica)". Assim, não tratamos de questões pertinentes à natureza e estrutura das teorias, e usamos o termo "teoria" em um sentido bastante amplo, para referir a corpos organizados - em diferentes graus de generalidade - de hipóteses, reivindicações, explicações e encapsulações de possibilidades. Quanto ao que denominamos "valores cognitivos", o M-CV trata os critérios para a avaliação cognitiva de uma teoria (isto é, a avaliação da teoria como portadora de conhecimento e entendimento de alguns fenômenos) como valores cognitivos (por exemplo, adequação empírica, poder explanatório, consistência e coerência), valores 
de um tipo fundamentalmente distinto dos valores éticos, sociais e de todos os outros tipos de valores. Por fim, a noção de "estratégia" ocupa um lugar central no MC-V. A pesquisa científica sempre é conduzida dentro de uma estratégia que (1) restringe os tipos de teorias (ou hipóteses) a serem considerados e possivelmente aceitos em um projeto de pesquisa, o que leva à especificação dos recursos conceituais disponíveis e dos tipos de possibilidades que se podem identificar, assim como dos tipos de modelos, analogias, experimentos, técnicas e simulações que podem ser usadas no curso da pesquisa; e (2) seleciona os tipos de dados empíricos que o cientista busca obter e relatar, assim como os fenômenos e aspectos a serem observados e pesquisados.

\section{As ETAPAS OU MOMENTOS DA ATIVIDADE GIENTÍFICA: \\ PAPÉIS DIFERENTES PARA DIFERENTES TIPOS DE VALORES}

De acordo com o M-GV, diferentes tipos de valores desempenham funções diferentes nas diferentes etapas de que é composta a atividade científica. É conveniente para os nossos fins distinguir cinco etapas (logicamente distintas, mas não temporalmente separadas):

$$
\begin{aligned}
& M_{1}-\text { da adoção da estratégia da pesquisa; } \\
& M_{2}^{2} \text { - do empreendimento da pesquisa; } \\
& M_{3}-\text { da avaliação cognitiva das teorias e hipóteses; } \\
& M_{4}-\text { da disseminação dos resultados científicos; } \\
& M_{5}-\text { da aplicação do conhecimento científico. }
\end{aligned}
$$

Só os valores cognitivos têm papéis legítimos na etapa $\mathrm{M}_{3}$, mas em todas as outras etapas, os valores éticos e sociais têm papéis legítimos e, por vezes, essenciais.

\subsection{A etapa $M_{3}$ DA AVALiação Gognitiva}

A avaliação cognitiva de uma teoria $(\mathrm{T})$ diz respeito à capacidade de T representar conhecimento e entendimento de domínios específicos de fenômenos (D). Trata-se da avaliação do grau de manifestação dos valores cognitivos em $\mathrm{T}$ a respeito de dados empíricos obtidos a partir da observação dos fenômenos do domínio específico D. Aceitar que $\mathrm{T}$ é uma teoria para o domínio $\mathrm{D}\left(\mathrm{T}_{\mathrm{D}}\right)$ é fazer o juízo de que $\mathrm{T}_{\mathrm{D}}$ pertence ao corpo de conhecimento científico estabelecido, isto é, de que $\mathrm{T}_{\mathrm{D}}$ é uma contribuição que se julga ser bem testada a partir dos processos de investigação (disponíveis em $\mathrm{M}_{2}$ ), e que não existe razão por ora para antecipar que mais pesquisa pudesse conduzir a sua re- 
jeição. No caso de T ser uma teoria universal (por exemplo, a teoria da mecânica clássica ou a teoria da relatividade), só $\mathrm{T}_{\mathrm{D}}$, para alguns $\mathrm{D}$, pode ser aceita nesse sentido nunca T propriamente dita, isto é, independente de um domínio de aplicação -, uma vez que $\mathrm{T}$ fica aberta à rejeição quando se realiza mais investigação de fenômenos que não pertencem ao domínio $\mathrm{D}$.

A aceitação de uma teoria é (ou deve ser) feita de acordo com o ideal da imparcialidade, o qual pode ser expresso como segue:

(1) T é corretamente aceita para D - ou $T_{D}$ é corretamente aceita como um item do conhecimento estabelecido - se e somente se T manifestar os valores cognitivos em alto grau, em grau mais alto do que as teorias rivais, à luz dos dados empíricos (E) relevantes e suficientes, obtidos da observação dos fenômenos do domínio D; e

(2) T é corretamente rejeitada para $\mathrm{D}$ se e somente se outra teoria $\left(\mathrm{T}_{1}\right)$ (inconsistente com T) manifesta os valores cognitivos em grau mais elevado para o domínio $\mathrm{D}$.

De acordo com a imparcialidade (ver fig. 1), para aceitar $T_{D}$ corretamente, só podemos recorrer aos dados empíricos (E) e aos valores cognitivos; não há papel legítimo para os valores éticos e sociais ou para as convicções metafísicas, juntamente com os valores cognitivos. Porém, é importante assinalar que a avaliação cognitiva não é o único tipo de avaliação feita de T, que também pode ser avaliada por seu significado, ou seja, por sua capacidade de ser aplicada (na etapa $\mathrm{M}_{5}$ ) para servir interesses desejados e visados. Entretanto, questões relacionadas ao significado são irrelevantes para a avaliação cognitiva.

\subsection{A etapa $M_{1}$ da adoção de estratégias de PEsquisa}

As pesquisas sobre tipos diferentes de fenômenos podem requerer a adoção de tipos diferentes de estratégias, o que talvez seja óbvio a respeito dos fenômenos investigados em disciplinas diferentes (basta pensar nas diferenças entre as estratégias da mecânica newtoniana, da química molecular, da mecânica quântica e da genética). Precisamos também de um tipo de estratégia para investigar as estruturas dos genomas das plantas, e de outro tipo de estratégia para as possibilidades dos agroecossistemas sustentáveis, um tipo de estratégia para obter conhecimento que contribui para a geração de inovações e outros tipos diferentes para a investigação dos riscos do uso das inovações, ou ainda, tipos de estratégias diferentes para a investigação do tratamento e da prevenção de doenças etc. 
Frequentemente, a escolha do domínio de fenômenos para investigação prioritária reflete juízos de valor ético e social, ao passo que a estratégia adotada deve ser adequada para investigá-los. Isso leva à situação comum de relações de reforço mútuo entre a adoção de uma estratégia (S) e a sustentação de uma perspectiva de valor - daqui em diante referida por " $\{\mathrm{V}\}$ " (na figura $1, \mathrm{~S} \longrightarrow\{\mathrm{V}\}$ ) -; e, assim, essas relações podem fornecer parte da explicação e justificação para a adoção de S. Contudo, o papel da $\{V\}$ não é suficiente para justificar a adoção de S por tempo indefinido. A longo prazo, a adoção de $\mathrm{S}$ depende de sua fecundidade, isto é, de sua capacidade em aumentar o corpo de conhecimento científico estabelecido; nesse sentido, há uma forte restrição empírica na adoção das estratégias.

\subsection{A etapa $\mathrm{M}_{2}$ De Desenvolvimento da Pesquisa}

Depois da adoção de $\mathrm{S}$, os valores éticos e sociais podem desempenhar uma variedade de papéis legítimos no empreendimento da pesquisa, particularmente na seleção dos objetos/fenômenos de pesquisa imediata. Os valores éticos e sociais influenciam quais são os objetos particulares investigados dentro do domínio geral selecionado na etapa $\mathrm{M}_{1} \mathrm{e}$, portanto, os objetos/fenômenos dos quais nós atualmente obtemos conhecimento científico. Contudo, o alcance da escolha aberta (em princípio) para os cientistas é muito grande, porque a tradição científica moderna sustenta o ideal da abrangência:

Em princípio, qualquer objeto/fenômeno do mundo - inclusive os fenômenos de importância no mundo da vida (e hipóteses sobre eles) e, portanto, fenômenos e objetos descobertos, produzidos ou propostos no curso de operações experimentais e de mensuração - pode ser submetido à pesquisa científica, com a esperança (pelo menos a longo prazo) de que ele pertença a um domínio para o qual uma teoria tornar-se-á aceita de acordo com a imparcialidade.

Também no desenvolvimento da pesquisa experimental, o valor ético e social de obter conhecimento científico passa a ser subordinado, por exemplo, à observância dos direitos humanos; é nesta etapa $\mathrm{M}_{2}$ que há um papel para os comitês e códigos de ética.

Finalmente, o valor ético e social tem a função de manter as condições favoráveis para a aceitação de acordo com a imparcialidade na etapa $M_{3}$. A aceitação de $T_{D}$ é um resultado de atividades de pesquisa que estão sujeitas a várias condições materiais, sociais e econômicas, e nas quais os investigadores têm vários interesses, motivações e objetivos. Assim, $\mathrm{T}_{\mathrm{D}}$ pode ser aceita, mas não de acordo com a imparcialidade, quan- 
do valores éticos e sociais vêm a desempenhar papéis ao lado dos valores cognitivos, por exemplo, quando não se reconhece que o significado é completamente irrelevante para a aceitação correta, ou quando a pesquisa fica incompleta (por exemplo, sobre a determinação dos riscos) em virtude dos interesses dos financiadores da pesquisa. Certas condições podem contribuir para eliminar esses mecanismos contrários à obtenção da imparcialidade. Há controvérsia sobre quais seriam essas condições; assim, para alguns, é o compromisso com o éthos científico, enquanto para outros é a supervisão democrática das atividades científicas conduzidas em instituições que oferece espaço para pesquisadores que sustentam um alcance de perspectivas de valor diferentes e que estabelecem estruturas para facilitar as interações críticas entre os pesquisadores. Seja como for, certas condições sociais e, portanto, a incorporação de certos valores éticos e sociais em instituições científicas contribuem causalmente para a obtenção da imparcialidade. Mas isso não implica que esses valores funcionem como critérios para a avaliação de teorias e hipóteses. Os valores cognitivos continuam sendo o único tipo de valores com tal função, mas por vezes compromissos com valores éticos e sociais contribuem para assegurar que os valores cognitivos desempenhem efetivamente essa função de modo correto.

$\mathrm{Na}$ etapa $\mathrm{M}_{2}$ a teoria $\mathrm{T}$ é adotada, desenvolvida, transformada e submetida a teste sob uma estratégia $S$, a qual é em parte adotada por causa de suas relações mutuamente reforçadoras com $\{\mathrm{V}\}$ e (algumas vezes) em virtude da expectativa de que as aplicações de T na etapa $M_{5}$ serão significativas para os interesses que refletem \{V\}. Entretanto, isso não implica que os valores de $\{\mathrm{V}\}$ estejam funcionando conjuntamente com os valores cognitivos na aceitação de $T_{D}$ na etapa $M_{3}$ (tal como representado na figura 1). A justificação racional de que $\mathrm{T}_{\mathrm{D}}$ é de fato um item do conhecimento científico estabelecido depende somente dos dados empíricos e dos valores cognitivos. Contudo, a explicação de por que a teoria se torna um item estabelecido não pode ser dissociada do papel de $\{\mathrm{V}\}$ na adoção de $\mathrm{S}$ e, portanto, do desenvolvimento de T. Assim, os valores éticos e sociais possuem um papel explicativo com relação à etapa $M_{3}$, mas não possuem um papel em conjunto com os valores cognitivos na avaliação cognitiva de $T_{D}$.

\subsection{A etapa $\mathrm{M}_{4}$ Da disseminaçÃo (Difusão) Dos Resultados Gientíficos}

A disseminação de resultados científicos dá origem a várias questões implicadas em valores éticos e sociais, porque esta etapa envolve a divulgação dos resultados da pesquisa por meio de publicações especializadas, o que constitui o sistema de comunicação interna à ciência, assim como a difusão de novos conhecimentos científicos na 
educação de novas gerações de pesquisadores ou ainda a divulgação dos conhecimentos científicos para o público leigo.

É nesta etapa que aparecem restrições ligadas a valores políticos e sociais. Por exemplo, com respeito à "classificação" de conhecimentos científicos como "secretos" por parte de governos tendo em vista fins militares ou, ainda, o sigilo de resultados mantidos na "ciência comercializada" por parte de corporações que financiam a pesquisa. Em ambos os casos, isso possui implicações para a possibilidade de obtenção da imparcialidade e de manifestação da neutralidade, além de representar uma transgressão óbvia da autonomia (cf. Mariconda, 2014).

\subsection{A etapa $M_{5}$ DA APlicação do Gonhegimento Gientífico}

Valores éticos e sociais penetram profundamente por toda a etapa $M_{5}$. A aplicação do conhecimento científico é ação prática; e toda ação é intencional e expressa certos ideais que conferem inteligibilidade e valor aos fins visados na ação. Uma aplicação sempre serve a interesses que refletem valores éticos e sociais específicos; é desenvolvida e implementada por causa dos benefícios esperados (por aqueles interesses) e da expectativa de que esses benefícios superem as possíveis consequências negativas implicadas nos seus efeitos colaterais, além da expectativa de que a proporção dos benefícios em relação aos malefícios seja maior do que se pode esperar de outras ações e práticas potencialmente competidoras (ver fig. 1).

Entretanto, as aplicações de $\mathrm{T}_{\mathrm{D}}$ também levantam questões de legitimidade, que vão bem além dos interesses de seus usuários potenciais e, também, além das consequências da aceitação de $\mathrm{T}_{\mathrm{D}}$ de acordo com a imparcialidade. $\mathrm{T}_{\mathrm{D}}$, quando aceita de acordo com a imparcialidade, serve para mostrar que certas aplicações são possíveis, que se pode aumentar sua eficácia e explicá-la. Mas, embora a eficácia técnica seja uma condição necessária para a legitimidade, ela não é suficiente para garantir a legitimidade de uma aplicação (como fica evidente no caso dos transgênicos discutido na seção 5). Juízos de legitimidade sempre envolvem considerações de valores éticos e sociais e também reivindicações sobre, por exemplo, efeitos danosos, riscos, benefícios e alternativas (todos os quais estão imbricados em considerações valorativas), que estão sujeitas à investigação empírica, mas que tipicamente não podem ser resolvidas por referência à própria teoria $\mathrm{T}$, ou por pesquisa conduzida sob a mesma estratégia que originou $\mathrm{T}$. 


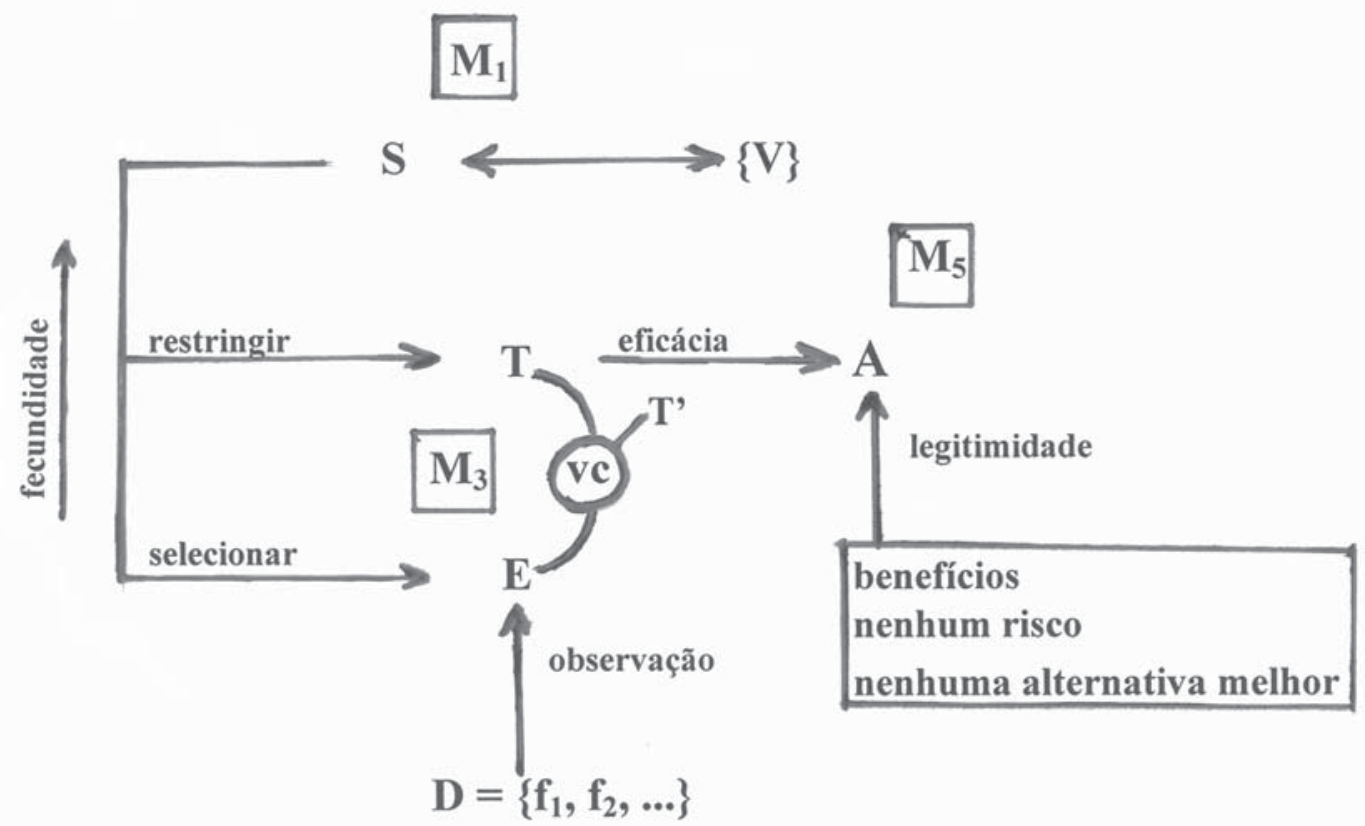

Figura 1. Representação das etapas $M_{1}, M_{3}$ e $M_{5}$.

$\mathrm{S}$ = estratégia apropriada para a investigação dos fenômenos $\left\{\mathrm{f}_{\mathrm{i}}\right\}$ do domínio $\mathrm{D}$;

$\mathrm{T}=$ uma teoria investigada sob $\mathrm{S} ; \mathrm{T}^{\prime}$ = outras teorias;

$\mathrm{E}$ = dados empíricos obtidos por observação dos $\left\{f_{\mathrm{i}}\right\}$ de $\mathrm{D}$;

$\{\mathrm{V}\}=$ uma perspectiva de valor;

$\mathbf{v e}=$ valores cognitivos;

A = aplicação.

Embora uma aplicação técnica/tecnológica sempre seja implementada para servir a certos interesses, a tradição da ciência moderna sustenta que, na etapa $M_{5}$, a neutralidade funciona como um ideal regulador, segundo o qual o conhecimento científico faz parte do patrimônio compartilhado da humanidade e todas as contribuições fazem parte do estoque comum de conhecimento. Segundo a neutralidade:

(1) Em princípio, toda perspectiva de valor (viável e sustentada nas atuais sociedades democráticas) está incorporada em práticas que podem ser informadas por alguns itens do corpo de conhecimento científico estabelecido ou que podem utilizar algumas aplicações do conhecimento científico; e (2) o corpo de conhecimento científico (como um todo) serve todas as perspectivas de valor $\{\mathrm{V}\}$ mais ou menos equitativamente, sem privilegiar algumas em detrimento de outras. 
É importante notar que isso não implica que cada item do conhecimento científico sirva (em princípio) equitativamente a todas as perspectivas de valor $\{V\}$. A neutralidade diz respeito à totalidade dos itens de conhecimento científico ou à totalidade das contribuições científicas e não a cada item tomado individualmente. Apenas alguns itens do conhecimento científico (por exemplo, aqueles ligados às curas de doenças) servem mais ou menos equitativamente a todas as $\{\mathrm{V}\}$, e alguns outros servem uma variedade de $\{\mathrm{V}\}$ além daquela que inicialmente motivou a aplicação técnica/tecnológica desses conhecimentos (com eficácia comprovada por métodos científicos), mas, de fato, muitos itens servem a uma $\{\mathrm{V}\}$, por exemplo, àquela do capital e do mercado, em detrimento de outras, por exemplo, a da justiça social e da sustentabilidade. Nossa formulação mostra-se consistente com esses fatos. Além disso, também é importante distinguir a neutralidade na aplicação da neutralidade cognitiva. Um item do conhecimento científico, aceito de acordo com a imparcialidade, não implica dedutivamente nenhum juízo de valor ético e social; não favorece, em virtude de suas consequências dedutivas, uma perspectiva de valor $\{\mathrm{V}\}$ em vez de outras. A neutralidade cognitiva é uma tese lógica (uma consequência lógica da imparcialidade) e, portanto, não pode fornecer apoio para a neutralidade na aplicação. A neutralidade pode funcionar como um ideal regulador, só se for possível mostrar por meio da investigação empírica que os desenvolvimentos científicos têm (ou podem ter) uma trajetória de aproximação a ela. Usaremos o M-CV para mostrar quais são as condições necessárias para assegurar a possibilidade da neutralidade funcionar como um ideal regulador (ver a seção 4).

Cabe ainda lembrar que além dos ideais já mencionados, a tradição científica moderna sustenta o ideal da autonomia para as práticas de pesquisa e para as instituições científicas.

As práticas e instituições científicas deveriam ser livres de interferência externa e de influência desproporcional de qualquer $\{\mathrm{V}\}$ (e de preferências pessoais), para permitir que (1) as questões de metodologia científica e os critérios para avaliar o conhecimento científico não possam ser resolvidos a partir de qualquer perspectiva ética (religiosa, política, social, econômica) ou de preferências pessoais, e que (2) as prioridades de pesquisa, para a atividade científica como um todo, não se tornem moldadas por perspectivas de valor privilegiadas, e que (3) as instituições científicas sejam constituídas de forma a poder resistir a interferências externas (não científicas).

A autonomia pode ser defendida como um ideal só até o ponto em que ela serve para fortalecer a imparcialidade e a neutralidade nas atividades cientificas. (Sobre autonomia, ver Lacey \& Mariconda, 2012; Oliveira, 2011). 


\section{O MODELO DA INTERAÇÃO E A GONGEPÇÃO DE PESQUiSA GIENTÍfICA}

O M-CV incorpora a seguinte concepção da pesquisa científica:

[PS ] A pesquisa científica é investigação empírica sistemática - que responde ao ideal da imparcialidade - (1) que é conduzida mediante o uso de quaisquer estratégias que sejam adequadas à obtenção de conhecimento e entendimento dos objetos/fenômenos investigados, onde (consistentemente com o ideal da abrangência) o alcance dos objetos investigados sempre está aumentando, frequentemente tendo em vista a aplicação prática e tecnológica do conhecimento; e (2) que assegura que toda perspectiva de valor será servida no maior grau possível por algumas aplicações e que, em princípio, serão mantidas as condições que possibilitariam que a neutralidade funcionasse como um ideal regulador.

A tese mais distintiva do M-CV é derivada da análise feita da etapa $\mathrm{M}_{1}$. Assim, (a) a estratégia adotada para um projeto de pesquisa deve ser adequada à luz das características dos fenômenos investigados; (b) a pesquisa sobre tipos diferentes de fenômenos pode requerer a adoção de tipos diferentes de estratégias, e (c) isso envolve relações de reforço mútuo entre a adoção de uma estratégia e a sustentação de uma perspectiva de valor. Até certo ponto, (a) e (b) não são controversas; a contribuição do M-CV consiste na introdução de (c) e na interpretação das teses (a) e (b) em termos de (c). Vamos denominar a combinação das teses (a), (b) e (c) de "tese do pluralismo estratégico" (ver fig. 2). O modelo tradicional da pesquisa científica, segundo o qual "a ciência é livre de valores”, pode ser interpretado como sutentando que não existem papéis legítimos para os valores éticos e sociais nas etapas $\mathrm{M}_{3}$ e $\mathrm{M}_{1}$ (cf. Lacey, 1999). Ninguém nega que existem papéis legítimos para esses valores nas outras etapas. O M-CV difere dessa concepção por permitir papéis legítimos para esses valores na etapa $\mathrm{M}_{1}$. Esta única diferença fundamental tem consequências profundas.

\subsection{As ESTRATÉgIAS DESGONTEXTUALIZADORAS}

À primeira vista, a ciência moderna, tal como praticada nas instituições científicas atuais, não se ajusta bem ao item (c) de nossa análise da etapa $M_{1}$. A maior parte da pesquisa científica moderna emprega um tipo especial de estratégias, às quais denominamos "estratégias descontextualizadoras" (SDs). As SDs restringem as teorias, que são investigadas e avaliadas, àquelas que podem representar os fenômenos e encapsular as suas possibilidades por referência a sua ordem causal subjacente, isto é, por refe- 

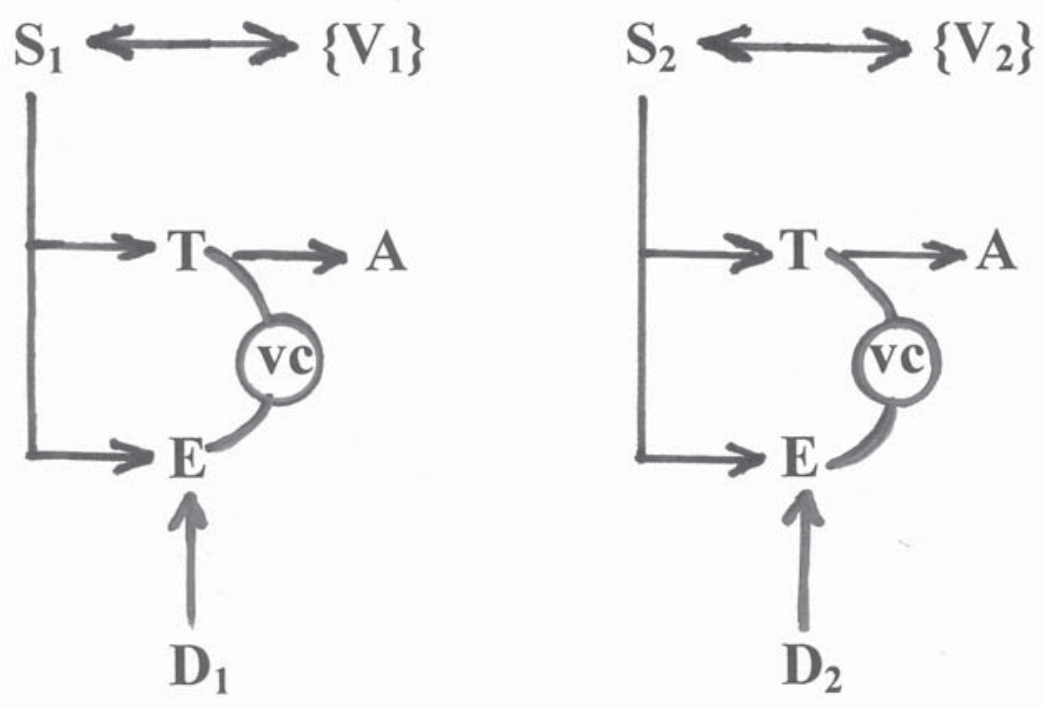

Figura 2. Representação do pluralismo estratégico.

$\mathrm{S}_{1}$ = estratégia apropriada para a investigação dos fenômenos de $\mathrm{D}_{1}$.

$\mathrm{S}_{2}=$ estratégia apropriada para a investigação dos fenômenos de $\mathrm{D}_{2}$.

$\mathrm{D}_{1}, \mathrm{D}_{2}$ - domínios de tipos diferentes de fenômenos.

Em alguns casos, $\left\{\mathrm{V}_{1}\right\} \neq\left\{\mathrm{V}_{2}\right\}$.

rência à estrutura subjacente dos fenômenos, aos processos e interações de seus componentes, e às leis que os governam expressas tipicamente em forma matemática (EPILs). Representar os fenômenos dessa maneira envolve descontextualizá-los, ou seja, os fenômenos são dissociados de qualquer lugar que possam ter no mundo da vida, de qualquer lugar que eles tenham com relação à organização social, vidas e experiências humanas, de qualquer vínculo com a agência humana, as qualidades sensoriais e o valor, e de quaisquer possibilidades que eles possam ter em virtude de seus lugares em contextos sociais, humanos e ecológicos particulares. Quanto aos dados empíricos, eles são selecionados, procurados e formulados utilizando categorias descritivas geralmente quantitativas, obtidas por meio de intervenções (frequentemente assistidas por computadores) de mensuração, instrumentais e experimentais.

Há uma variedade de SDs, de modo que as estratégias da mecânica newtoniana, da química molecular, da mecânica quântica e da genética são diferentes em função dos itens (a) e (b) acima. E, sem dúvida, as SDs são fecundas e versáteis; fecundas, porque capacitam a acumulação de uma quantidade enorme de conhecimento das EPILs dos fenômenos do mundo, tornam possível muitas descobertas dos componentes e leis dessa ordem causal subjacente e identificam possibilidades para a ação humana previamente desconhecidas; versáteis, porque novos tipos de SDs surgem regularmente para 
tratar de fenômenos que não puderam ser entendidos sob as SDs antecedentes. Por exemplo, a metodologia newtoniana substitui a metodologia cartesiana para explicar os movimentos dos planetas; a metodologia da mecânica quântica, que permite o uso de leis probabilísticas, foi introduzida para tratar de fenômenos do domínio subatômico, e alguns biólogos teóricos rejeitam metodologias reducionistas em favor de modelos que incorporam a complexidade matemática para entender fenômenos tais como o desenvolvimento dos organismos.

O alcance das SDs continua a expandir-se, aparentemente sem nenhum limite. A natureza é vista como um imenso repositório de possibilidades e, no curso dos desdobramentos das pesquisas conduzidas sob as SDs, utilizam-se as práticas experimentais e tecnológicas que nos tornam capazes de realizar sempre mais dessas possibilidades, inclusive as possibilidades de novos tipos de fenômenos (tecnocientíficos) que se podem criar no curso dessas práticas. O poder da abordagem metodológica baseada no emprego das SDs, e na sua fecundidade e versatilidade, de abranger cada vez mais variedades de fenômenos tem sempre aumentado, e de maneiras imprevisíveis, vinculadas às invenções de novas variedades de SDs. No entanto, isso não implica (mesmo em princípio) que sejamos capazes de entender todos os fenômenos, ou todos seus aspectos, através do uso de SDs. A ausência de um limite desse tipo não implica que não haja fronteiras que não podem ser atravessadas (cf. Lacey, 2009). Igualmente não implica que (mesmo a longo prazo) as SDs serão capazes de fornecer a compreensão de todos os fenômenos.

\subsection{As estratégias DESGONTEXTUALIZADORAS,}

AS ESTRATÉGIAS SENSÍVEIS AO CONTEXTO E O IDEAL DA ABRANGÊNCIA

De fato, faltam às SDs os recursos necessários para pesquisar aqueles fenômenos cujas identidades estão intrinsecamente vinculadas a seus contextos. Por exemplo, os efeitos sistêmicos da mudança social não podem ser tratados por SDs, como tampouco os fenômenos nos agroecossistemas sustentáveis. Mesmo no caso das consequências (riscos e malefícios) ocasionadas pelo uso das inovações tecnocientíficas, as SDs só podem investigar as consequências de certo produto ou aplicação que têm mecanismos físicos, químicos e biológicos. Assim, por exemplo, no caso das sementes transgênicas, as SDs permitem investigar as suas propriedades genômicas e moleculares, mas não os efeitos de seu uso causados por mecanismos socioeconômicos, ligados, por exemplo, aos direitos de propriedade intelectual, nem seus efeitos sobre a segurança alimentar das populações. As SDs tampouco podem investigar as causas sociais de fenômenos problemáticos como, por exemplo, uma epidemia de gripe, ou as condições necessá- 
rias para tomar medidas efetivas para proteger a saúde pública em regiões pobres. Por fim, a ação humana, inclusive das atividades de pesquisa conduzidas sob as SDs, só pode ser explicada com o uso de categorias intencionais, de modo que as SDs não permitem entender as atividades humanas envolvidas particularmente na condução de pesquisa sob as próprias SDs (por exemplo, na etapa $\mathrm{M}_{2}$, a construção dos espaços experimentais, a determinação de suas condições limítrofes e as condições iniciais de eventos experimentais e, na etapa $M_{1}$, a adoção de estratégias) e todas as consequências significativas da aplicação do conhecimento que obtemos nessa pesquisa. Portanto, a adoção quase exclusiva das SDs não está de acordo com o ideal da abrangência.

Além disso, algumas vezes o conhecimento/entendimento dos fenômenos pode ser obtido utilizando estratégias sensíveis ao contexto (SCs), que não são redutíveis às SDs, gerando conhecimento confirmado de acordo com a imparcialidade. Existem algumas SCs fecundas. Lacey (2010, parte 2; 2006) usa frequentemente a agroecologia como ilustração. As estratégias da agroecologia permitem a investigação de agroecossistemas levando em conta simultaneamente as dimensões de produtividade, sustentabilidade ecológica, preservação da biodiversidade, saúde social e fortalecimento da agência e cultura de grupos humanos locais, frequentemente com o fim de descobrir um equilíbrio ótimo, no qual todas as dimensões são mantidas e fortalecidas, e as práticas da agricultura agroecológica melhoradas (cf. Lacey, no prelo a). Esses exemplos mostram que algumas vezes existe a opção de adotar SCs fecundas para investigar fenômenos que estão fora do alcance das SDs; e não utilizar essa opção prejudica o ideal da abrangência. Contudo, nas instituições científicas predominantes, essa opção não é geralmente reconhecida.

No mainstream científico não é comum reconhecer que existe a etapa $M_{1}$, logicamente distinta da etapa $\mathrm{M}_{2}$, na qual se tomam decisões acerca de qual estratégia adotar. Tampouco se reconhece que alguns tipos de fenômenos precisam ser investigados sob as SCs. Embora (como foi apontado acima) exista uma variedade de SDs, raramente se contempla para uma área de pesquisa a possibilidade de que existam ocasiões para a escolha deliberada da estratégia (enquanto distinta dos métodos específicos que podem ser escolhidos em $\mathrm{M}_{2}$ ) a ser usada em um projeto de pesquisa; ao contrário, as estratégias atualmente usadas são consideradas como determinadas pelo curso do desenvolvimento histórico interno a uma área de pesquisa (disciplina), submetida unicamente à fecundidade a longo termo.

Parece ser implícito ao "senso comum" da ciência moderna que a adoção de SDs faz parte essencial da metodologia científica, de modo que a concepção da natureza da pesquisa científica corresponde mais à seguinte definição $\left[\mathrm{PS}_{2}\right]$, do que à definição $\left[\mathrm{PS}_{1}\right]$ formulada acima. 
[PS $\left.{ }_{2}\right]$ A pesquisa científica é a investigação empírica sistemática - que responde ao ideal da imparcialidade - conduzida mediante o uso das SDs, onde o alcance dos objetos investigados está sempre aumentando, frequentemente tendo em vista a aplicação prática e tecnológica do conhecimento.

Para ambas as concepções, $\left[\mathrm{PS}_{1}\right]$ e $\left[\mathrm{PS}_{2}\right]$, as estratégias adotadas podem variar dependendo das características dos fenômenos investigados. Contudo, no caso de [PS 2 ], a possibilidade de variação é muito menor, não se estendendo até a possibilidade de incluir as SCs. De acordo com $\left[\mathrm{PS}_{2}\right.$ ], as SCs não fazem parte da metodologia "científica"; a pesquisa científica deve ser empírica (como em $\left[\mathrm{PS}_{1}\right]$ ), mas (de modo diferente de $\left[\mathrm{PS}_{1}\right]$ ) também envolve a descontextualização. ${ }^{\mathbf{}}$

Argumentamos acima que o alcance das SDs, embora sem limites aparentes, tem uma fronteira e que precisamos de algumas SCs para ultrapassar essa fronteira. Aqueles que afirmam a concepção $\left[\mathrm{PS}_{2}\right]$ tendem a rejeitar esse argumento com base em sua convicção de que se trata somente de um estágio temporário e de que, com o aumento da versatilidade das SDs e de sua capacidade de tratar da complexidade, acabaremos vendo que "ser essencialmente contextualizado" indica apenas a grande complexidade das EPILs de certos fenômenos, e não uma fronteira para o alcance das SDs (atuais e futuras). Manter essa convicção não implica contradição ou desacordo com os dados empíricos disponíveis e permite considerar a abrangência como um horizonte bastante distante para a pesquisa conduzida sob as SDs. Todavia, essa convicção representa uma visão metafísica - uma versão contemporânea da metafísica materialista que influenciou profundamente a tradição científica (cf. Lacey, 2009; Lacey \& Mariconda, 2012), que não é certamente um resultado da pesquisa científica aceita de acordo com a imparcialidade, mas uma convicção metafísica. Por isso, o fato de que reivindicações articuladas com as categorias distintas das SCs não instanciam essa metafísica - não

\footnotetext{
1 No "senso comum" da ciência moderna, atribui-se algum papel para as ciências sociais que obviamente devem desenvolver SCs. Entretanto, a pesquisa conduzida nas ciências sociais tende a ser considerada como separada da pesquisa conduzida sob as SDs nas ciências naturais; há uma tendência a considerar questionável o estatuto "científico" das ciências sociais e seus resultados não são considerados (por exemplo, nos corpos regulatórios) com a mesma seriedade que os resultados obtidos sob as SDs. Não discutiremos isso neste artigo. Aqui estamos especialmente interessados no desenvolvimento de SCs para investigar os efeitos da utilização de inovações técnicas e científicas (que possuem dimensões físicas/químicas/biológicas essenciais), que são produzidos por mecanismos socioeconômicos, isto é, por fenômenos do mundo da vida nos quais não é possível separar os componentes científicos naturais e sociais. Por exemplo, as SCs desenvolvidas (juntamente com SDs) para investigar os efeitos a longo prazo sobre a fertilidade do solo causados pelo plantio de monoculturas e o uso regular de agrotóxicos. Segundo o M-CV, com seu pluralismo estratégico (ver seção 4), não se pode traçar uma linha divisória clara entre as ciências naturais e sociais, e as investigações "científicas" não podem ser divididas naquelas que caem sob uma categoria ou sob a outra.
} 
fornece uma razão apropriada para rejeitar os resultados obtidos de acordo com a imparcialidade sob as SCs. A questão da fecundidade das SCs - e a admissibilidade de [PS $]$ - só pode ser resolvida a partir da investigação empírica, e não por meio da admissão de um papel para convicções metafísicas ao lado ou acima dos valores cognitivos.

\subsection{Explicação da PRIORIdAde, até o PONTO dA EXClusividade, GONGEDIDA ÀS ESTRATÉGIAS DESGONTEXTUALIZADORAS}

Por que adotar a concepção $\left[\mathrm{PS}_{2}\right]$ da natureza da pesquisa científica, em vez da concepção mais ampla $\left[\mathrm{PS}_{1}\right]$ ? Como explicar a hegemonia de $\left[\mathrm{PS}_{2}\right]$ nas instituições predominantes atuais? Como justificar racionalmente essa hegemonia?

Aqui surge a importância do item (c) do pluralismo estratégico (exposto ao final da seção 3), que propõe que a adoção de uma estratégia mantém relações de reforço mútuo com a sustentação de uma perspectiva de valor $\{\mathrm{V}\}$. A adoção de $\left[\mathrm{PS}_{2}\right]$ esconde, particularmente, o papel desempenhado na ciência moderna pelo interesse no controle dos objetos naturais, deixando subentendido que existem relações de reforço mútuo entre a adoção das SDs e a sustentação da perspectiva de valor do progresso tecnológico $\left\{\mathrm{V}_{\mathrm{PT}}\right\}$, a qual, no mundo neoliberal atual, tende a ser interpretada à luz da perspectiva de valor do capital e do mercado $\left\{\mathrm{V}_{\mathrm{C \& M}}\right\}$. (Na figura 3, isso é representado por SDs $\left.\longleftrightarrow\left\{\mathrm{V}_{\mathrm{PT}}\right\} \longleftrightarrow\left\{\mathrm{V}_{\mathrm{C \& M}}\right\}\right)$.

$\mathrm{Na}\left\{\mathrm{V}_{\mathrm{PT}}\right\}$, o exercício do controle sobre os objetos naturais torna-se por si mesmo um valor social que não é subordinado de forma sistemática e geral a outros valores sociais, e atribui-se um alto valor ético às inovações que aumentam as capacidades humanas de exercer controle sobre os objetos naturais, à penetração cada vez maior de tecnologias em sempre mais domínios da vida cotidiana, da experiência humana e das instituições sociais, e à definição de problemas em termos que permitam soluções tecnocientíficas.

É fundamental lembrar que não se trata de que a pesquisa conduzida sob as SDs seja feita (sempre ou necessariamente) para o fim de fortalecer $\left\{\mathrm{V}_{\mathrm{PT}}\right\}$ (muita "ciência básica" procede independentemente de questões de aplicação). Trata-se antes de que existem relações de reforço mútuo entre a adoção das SDs e a sustentação de $\left\{\mathrm{V}_{\mathrm{PT}}\right\}$; por um lado, o uso das SDs produz resultados que, na aplicação servem especialmente bem a $\left\{\mathrm{V}_{\mathrm{PT}}\right\}$ (cf. a seção 3.4 adiante), as aplicações contribuem para fortalecer as instituições que incorporam $\left\{\mathrm{V}_{\mathrm{PT}}\right\}$ e a sustentação de $\left\{\mathrm{V}_{\mathrm{PT}}\right\}$ contribui para o endossamento da legitimidade das aplicações; e, por outro lado, esses mesmos resultados conduzem a 
inovações técnicas nos instrumentos e equipamentos que desempenham papéis essenciais (na etapa $\mathrm{M}_{2}$ ) para a pesquisa conduzida sob as SDs.

Essas relações de reforço mútuo fornecem a chave para explicar a hegemonia de $\left[\mathrm{PS}_{2}\right.$ ] e que as SDs sejam adotadas quase com exclusividade na pesquisa conduzida nas instituições científicas. A fecundidade e a versatilidade das SDs e seu potencial de desenvolvimento praticamente ilimitado são partes da explicação, além do fato de que provavelmente todo mundo valoriza a utilidade das aplicações de algum conhecimento (em medicina, agricultura, comunicações etc.) confirmado segundo as SDs. Isso explica o interesse de muita pesquisa conduzida sob as SDs, mas não a adoção das SDs pelas instituições científicas em detrimento das SCs e a rejeição das credenciais científicas das SCs. Para explicar essa exclusividade das SDs, precisamos também fazer recurso aos dois seguintes fatos: (1) que tanto $\left\{\mathrm{V}_{\mathrm{PT}}\right\}$ como $\left\{\mathrm{V}_{\mathrm{C \& M}}\right\}$ estão bem incorporadas nas instituições sociais e econômicas predominantes atuais, e (2) que existem as relações de reforço mútuo acima referidas.

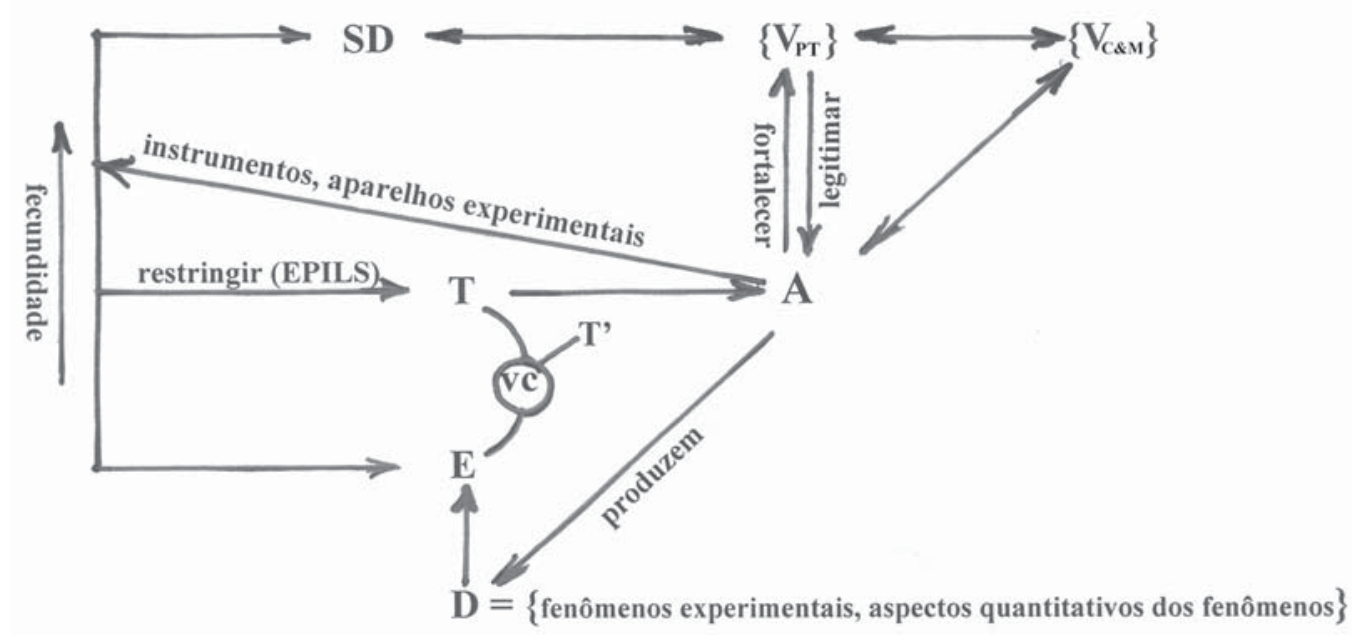

Figura 3. Representação esquemática do circuito de pesquisa de uma estratégia descontextualizadora SD.

O M-CV não é um modelo linear. Tal como é representado na figura 3, as relações de reforço mútuo localizam-se em um tipo de circuito fechado, no qual podemos mover-nos de um elemento a qualquer outro com movimentos em ambas as direções (por exemplo: $\left\{\mathrm{V}_{\mathrm{PT}}\right\} \longrightarrow \mathrm{SD} \longrightarrow \mathrm{T} \longrightarrow \mathrm{A} \longrightarrow\left\{\mathrm{V}_{\mathrm{PT}},\right\}$, e na direção inversa); e podemos entrar no circuito a qualquer ponto. A ciência que incorpora $\left[\mathrm{PS}_{2}\right]$ aparece como uma multiplicidade de práticas complementares em interação (teóricas, experimentais, 
aplicadas, de deliberações sobre a metodologia, institucionais científicas/comerciais/ governamentais). A representação em termos desse circuito fechado - e o poder das instituições que o mantêm - fortalece nossa explicação porque, dado que o cientista é educado e trabalha no seio dessas instituições, torna-se difícil pensar e agir fora desse circuito fechado.

\subsubsection{As ESTRATÉGIAS DESGONTEXTUALIZADORAS E O IDEAL DA NEUTRALIDADE}

O uso quase exclusivo das SDs produz resultados que não só servem especialmente bem aos interesses ligados a $\left\{\mathrm{V}_{\mathrm{PT}}\right\}$ e $\left\{\mathrm{V}_{\mathrm{C \& M}}\right\}$, mas frequentemente também servem esses interesses ao custo dos interesses vinculados a outras perspectivas de valor, por exemplo, a perspectiva de valor da justiça social, participação democrática e sustentabilidade $\left\{V_{\text {JSPDS }}\right\}$ (cf. Lacey, neste número). O uso dos transgênicos na agricultura, por exemplo, é valorizado pelas corporações do agronegócio e seus clientes (que incorporam a $\left\{\mathrm{V}_{\mathrm{C \& M}}\right\}$ ), mas não pelos movimentos sociais (que incorporam a $\left\{\mathrm{V}_{\text {JSPDS }}\right\}$ ) que enfatizam a agroecologia, porque o uso dos transgênicos solapa seus interesses. De modo inverso, onde $\left\{\mathrm{V}_{\mathrm{PT}}\right\}$ e $\left\{\mathrm{V}_{\mathrm{C} \& \mathrm{M}}\right\}$ são bem incorporadas, a agroecologia e a pesquisa conduzida sob as estratégias agroecológicas $\left(\mathrm{S}_{\mathrm{AE}}\right)$ - que são exemplos de $\mathrm{SCs}$ - não têm interesse (e, portanto, não ganham apoio), sendo excluídas da consideração, não porque as pesquisas conduzidas dentro delas não conseguiram demonstrar sua fecundidade, mas por causa do conflito de $\left\{\mathrm{V}_{\mathrm{PT}}\right\}$ e $\left\{\mathrm{V}_{\mathrm{C} \& \mathrm{M}}\right\}$ com os valores associados às SCs. Contudo, a menos que a pesquisa científica também seja conduzida para produzir conhecimento que sirva bem aos interesses ligados a $\left\{\mathrm{V}_{\text {JSPDS }}\right\}$ e outras $\{\mathrm{V}\}$, a neutralidade não pode funcionar como um ideal regulador; portanto, não pode funcionar assim nas instituições nas quais a $\left[\mathrm{PS}_{2}\right.$ ] é hegemônica, porque não faz parte de sua prática incluir o uso das SCs. Segue-se que se a hegemonia de $\left[\mathrm{PS}_{2}\right]$ fosse justificada, então a neutralidade seria um ideal ilusório.

\section{4 É POSSÍVEL JUSTIFIGAR RAGIONALMENTE A PRIORIDADE, ATÉ O PONTO DA EXGLUSIVIDADE, GONGEDIDA ÀS SDs?}

Justificação racional não é a mesma coisa que explicação. A partir de nossa explicação podemos obter a justificação para o privilégio dado às SDs, somente se existirem boas razões para sustentar $\left\{\mathrm{V}_{\mathrm{PT}}\right\}$ e para incorporar amplamente os valores de $\left\{\mathrm{V}_{\mathrm{PT}}\right\}$ nas instituições sociais, mesmo que em detrimento da incorporação social de $\left\{\mathrm{V}_{\text {JSPDS }}\right\}$ e de ou$\operatorname{tras}\{V\}$. Tais razões, se existirem, dependerão da aceitação de certas propostas $\mathrm{P}-\left\{\mathrm{V}_{\mathrm{PT}}\right\}$ entre as quais se incluem as seguintes: 
$\mathrm{P}-\left\{\mathrm{V}_{\mathrm{PT}}\right\}$ : (1) $\mathrm{O}$ controle é uma postura caracteristicamente humana em relação aos objetos naturais. O exercício do controle e, acima de tudo, o engajamento na pesquisa e o desenvolvimento de projetos tecnológicos, nos quais nosso poder de controle é ampliado, são formas essenciais e primárias pelas quais nos expressamos como seres humanos modernos, formas nas quais são cultivadas "virtudes" pessoais como criatividade, inventividade, iniciativa, ousadia diante dos riscos, autonomia e racionalidade.

(2) A inovação tecnológica fornece benefícios que contribuem para o bemestar dos seres humanos em geral, servindo, assim, aos interesses de todas as $\{\mathrm{V}\}$.

(3) Soluções tecnológicas podem ser encontradas para virtualmente todos os problemas, inclusive aqueles ocasionados pelos efeitos colaterais ou indesejados das próprias implementações tecnocientíficas, e não há outras fontes de soluções para muitos problemas sérios no mundo de hoje.

(4) Não existem possibilidades significativas de realização no futuro previsível para perspectivas de valor que não incluam $\left\{\mathrm{V}_{\mathrm{PT}}\right\}\left(\mathrm{e}\left\{\mathrm{V}_{\mathrm{C \& M}}\right\}\right)$ (cf. Lacey, 2010, p. 39).

Os itens de $\mathrm{P}-\left\{\mathrm{V}_{\mathrm{PT}}\right\}$ são propostas abertas à investigação empírica. Se eles forem desconfirmados no curso da investigação empírica, então a sustentação de $\left\{\mathrm{V}_{\mathrm{PT}}\right\}$ será contrária ao bom senso. Nesse sentido, os itens são pressupostos da sustentação de $\left\{\mathrm{V}_{\mathrm{PT}}\right\}$. Apesar do papel que possuem no discurso político sobre a ciência, não há muito interesse em sua investigação empírica nas instituições científicas dominantes, e poucos recursos financeiros são disponibilizados para tal investigação. $\mathrm{P}-\left\{\mathrm{V}_{\mathrm{PT}}\right\}$ parece ser aceito (sem base em investigação) em virtude do papel que ele tem na legitimação das instituições atualmente predominantes; o que não é uma aceitação de acordo com a imparcialidade. Além disso, uma vez que os itens de $\mathrm{P}-\left\{\mathrm{V}_{\mathrm{PT}}\right\}$ são pressupostos acerca de fenômenos sociais e históricos, seria necessário adotar SCs apropriadas para sua investigação; mas isso não pode acontecer onde $\left[\mathrm{PS}_{2}\right]$ é hegemônica. A explicação sugerida da aceitação de $\mathrm{P}-\left\{\mathrm{V}_{\mathrm{PT}}\right\}$ tem base no registro empírico (social e histórico) e requer a utilização de algumas SCs. Utilizando só as categorias admissíveis dentro das SDs, não podemos explicar seu uso quase exclusivo - porque as próprias atividades científicas estão intrinsecamente vinculadas a seus contextos. Quando se aceita [PS $\left.{ }_{2}\right]$, aceita-se que o fenômeno da adoção da $\left[\mathrm{PS}_{2}\right]$ não pode ser entendido no curso da pesquisa científica. Assim, o papel de $\mathrm{P}-\left\{\mathrm{V}_{\mathrm{PT}}\right\}$ indica uma etapa que fica fora do circuito fechado da figura 3 , uma etapa que representa a possibilidade de romper o circuito na direção da adoção de [PS $]$ (ver a figura 4). 
Não podemos justificar racionalmente a hegemonia de $\left[\mathrm{PS}_{2}\right]$ sem o uso de algumas SCs. Mas o uso de SCs implica a rejeição de $\left[\mathrm{PS}_{2}\right]$ em favor de $\left[\mathrm{PS}_{1}\right]$; o que é completamente consistente com o uso exclusivo das SDs para a investigação de certos domínios de fenômenos, e o papel confirmado das SDs para o alcance das estratégias que compõem o pluralismo estratégico. Confrontamo-nos, assim, com um dilema: ou aceitamos a hegemonia de $\left[\mathrm{PS}_{2}\right]$ sem explicação e justificação racional, ou seja, dogmaticamente ou por estipulação, ou aceitamos um papel para algumas SCs e exploramos a complementaridade entre as SDs e as SCs em pesquisa comprometida com [PS $]$. Podemos sem contradição estipular que a pesquisa científica é aquela que incorpora $\left[\mathrm{PS}_{2}\right]$, mas ao preço da rejeição dos ideais de abrangência e de neutralidade, reconhecendo a incapacidade da "ciência" de avaliar o significado das aplicações do conhecimento científico e de fornecer orientações confiáveis para a ação e para as políticas sobre a aplicação do conhecimento científico. Dissemos (no início da seção 3.3.1) que, à primeira vista, a ciência moderna, tal como praticada pelas instituições cientificas atuais, não se ajusta bem à proposta do M-CV de que existem relações de reforço mútuo entre a adoção de uma estratégia e a sustentação de uma perspectiva de valor $\{\mathrm{V}\}$. Mas mostramos também que a referência a essas relações de reforço mútuo entre a adoção das SDs e a sustentação de $\left\{\mathrm{V}_{\mathrm{PT}}\right\}$ serve para explicar aspectos importantes das atividades conduzidas no seio das instituições cientificas contemporâneas.

\section{O PLURALISMO ESTRATÉGigo}

O M-CV incorpora a concepção $\left[\mathrm{PS}_{1}\right]$ da natureza da pesquisa científica e permite um tipo de pluralismo estratégico que não inclui apenas o alcance das SDs atualmente desenvolvidas, mas, sobretudo, uma variedade de SCs fecundas, que complementam as SDs. De acordo com M-CV, é comum existirem relações de reforço mútuo entre a adoção de uma estratégia S e a sustentação de uma perspectiva de valor \{V\} (o que representamos esquematicamente na figura 1 por $\mathrm{S} \longrightarrow\{\mathrm{V}\})$. Nossa explicação para o uso quase exclusivo das SDs pelas instituições científicas utiliza as relações $\mathrm{SDs} \longrightarrow \mathrm{V}_{\mathrm{PT}}$ $\longrightarrow \mathrm{V}_{\mathrm{C} \& \mathrm{M} \cdot}{ }^{2}$

Temos aqui a pretensão de mostrar as possibilidades abertas pelo M-CV, não a de identificar todas as variedades de SCs potencialmente fecundas. Porém, isso é sufi-

2 Em alguns artigos do dossiê publicado na revista Estudos Avançados, explora-se uma variedade de relações SCs $\longleftrightarrow\{\mathrm{V}\}: \mathrm{S}_{\mathrm{AE}} \longleftrightarrow \mathrm{V}_{\text {JSPDS }} ; \mathrm{S}_{\text {saúde pública }} \longrightarrow$ saúde dos pobres; $\mathrm{S}_{\text {tecnologia social }} \longrightarrow$ disponibilidade para todos (especialmente os excluídos) das condições necessárias para o bem-estar; $\mathrm{S}_{\text {conhecimento indigena }} \longrightarrow \mathrm{V}_{\text {JSPDS }}$, valores culturais tradicionais. 
ciente para indicar que a adoção de $\left[\mathrm{PS}_{1}\right]$ e o reconhecimento do pluralismo estratégico abrem a possibilidade de reabilitar o ideal regulador da neutralidade. Essa possibilidade depende do alcance das perspectivas de valor $\{\mathrm{V}\}$ que estão vinculadas a estratégias fecundas: quanto mais $\{\mathrm{V}\}$ viáveis e sustentadas nas sociedades democráticas atuais, que têm relações de reforço mútuo com estratégias fecundas, maior pode ser a aproximação à neutralidade. E isso é um ideal que, sendo viável, seria importante para regular a conduta da ciência em uma sociedade democrática. O pluralismo estratégico não só abre a possibilidade de reabilitação do ideal da neutralidade, mas também do ideal da abrangência, desde que as SCs tornem possível a obtenção de conhecimento de fenômenos intrinsecamente ligados a seus contextos, os quais não podem ser tratados sob as SDs.

A aceitação do pluralismo estratégico não envolve geralmente a rejeição do uso das SDs em favor do uso de estratégias alternativas, nem a simples adição de uma variedade de SCs às SDs de modo a aumentar a variedade das estratégias utilizadas, mas a introdução de um alcance suficiente para as SCs complementarem as SDs. As SDs são bem adequadas para a investigação das EPILs dos fenômenos, mas precisamos usar algumas SCs para investigar aqueles fenômenos que não podem ser dissociados de seus contextos, por exemplo, os componentes de agroecossistemas sustentáveis, os riscos ocasionados no contexto de uso de inovações tecnocientíficas, a rede social causal de doenças e as medidas para melhorar a saúde pública, e as práticas da tecnologia social. Assim, geralmente, a pesquisa conduzida sob as SCs utiliza conhecimento obtido sob as SDs. Na agroecologia, por exemplo, o conhecimento dos componentes minerais, das bactérias etc. dos solos; na saúde pública, o conhecimento dos vírus que causam infecções etc. Nesse sentido, as SDs devem ser consideradas centrais para a investigação científica, mas isso não é a mesma coisa que atribuir-lhes prioridade até ao ponto de serem exclusivas. A introdução das SCs muda o significado da pesquisa conduzida sob as SDs; assim, em vez de exclusividade, as SDs passam a fazer parte de uma balança com as SCs. A adição das SCs provavelmente reduziria o financiamento disponível para a pesquisa sob as SDs, o que criaria a necessidade de tomar novas decisões acerca das prioridades de pesquisa, especialmente daquelas pesquisas ocasionadas pelo conflito entre $\left\{\mathrm{V}_{\mathrm{PT}}\right\} /\left\{\mathrm{V}_{\text {C\&M }}\right\}$ e $\left\{\mathrm{V}_{\text {JSPDS }}\right\}$ e, consequentemente, o novo equilíbrio obtido precisaria estabelecer compromissos no domínio dos valores e envolver alguma limitação da manifestação de $\left\{\mathrm{V}_{\mathrm{PT}}\right\}$ e $\left\{\mathrm{V}_{\mathrm{C \& M}}\right\}$, tal como a limitação sugerida pelo Princípio de Precaução, com implicações profundas para a identificação de pesquisa significativa e relevante (Lacey, neste número). 


\section{IMPARGIALIDADE: AGEITAÇÃo E ENDOSSAMENTO}

O uso quase exclusivo das SDs implica a rejeição da neutralidade como um ideal regulador da pesquisa cientifica (ver a seção 3.3.1). Ele cria também ameaças à imparcialidade na etapa $M_{5}$ das atividades conduzidas nas instituições científicas que mantêm a hegemonia de $\left[\mathrm{PS}_{2}\right]$.

Não há dúvida de que, sob as SDs, muitas teorias são aceitas de acordo com a imparcialidade para muitos domínios de fenômenos. Essas teorias podem geralmente servir para explicar bem a eficácia de suas aplicações, mas não tratam de várias questões, tais como aquelas sobre os efeitos danosos, os riscos e as alternativas, que são pertinentes à legitimidade de sua implementação (ver a discussão acerca da etapa $M_{5}$ na seção 2.5). Por exemplo, a eficácia de certos usos dos transgênicos é bem explicada em teorias da biologia molecular e da biotecnologia (que usam variedades das SDs), mas a legitimidade dos usos depende não só de sua eficácia, mas também das reivindicações de que seu uso produz benefícios maiores do que as abordagens agrícolas alternativas, e que sua produção, distribuição e consumo não ocasionam riscos sérios, nem causam efetivamente danos sérios, que não possam ser monitorados adequadamente à luz de regulamentos bem feitos. As mesmas teorias que explicam a eficácia têm pouca relevância para tratar dessas questões pertinentes à legitimidade que, por dizerem respeito a fenômenos ecológicos e sociais, somente podem ser investigadas empiricamente com o uso das SCs apropriadas.

Não obstante, em deliberações sobre a legitimidade da implementação de inovações tecnocientíficas (tais como os transgênicos) realizadas nas instituições comprometidas com $\left[\mathrm{PS}_{2}\right]$, é comum reivindicar que não existem alternativas viáveis nem riscos sérios. (Elas serão aqui designadas como "reivindicações de legitimidade"). Contudo, na ausência de resultados obtidos sob as SCs, as reivindicações de legitimidade não podem representar hipóteses aceitas de acordo com a imparcialidade. Apesar disso, elas tendem a ser afirmadas em nome da autoridade da ciência, embora nos pareça que são aceitas (sem base adequada em pesquisa) porque a negação delas discorda do "senso comum" da ciência, especialmente dos itens (3) e (4) de P- $\left\{\mathrm{V}_{\mathrm{PT}}\right\}$ (ver a seção 3.4), de modo que não são aceitas de acordo com a imparcialidade. Analogamente ao papel de $\mathrm{P}-\left\{\mathrm{V}_{\mathrm{PT}}\right\}$ na etapa $\mathrm{M}_{1}$, o papel das reivindicações de legitimidade indica um aspecto (com impacto na etapa $\mathrm{M}_{5}$ ), que representa a possibilidade de romper o circuito fechado (ver a figura 3) na direção da adoção de [PS $]$ (ver a fig. 4).

$\mathrm{O}$ pluralismo estratégico de $\mathrm{M}-\mathrm{CV}$ abre a possibilidade de aceitar ou rejeitar as reivindicações de legitimidade (e $\mathrm{P}-\left\{\mathrm{V}_{\mathrm{PT}}\right\}$, bem como os pressupostos das perspectivas vinculadas às várias $\mathrm{SCs}$ ) de acordo com a imparcialidade. Porém, isso permanece frequentemente apenas uma possibilidade distante, de pouca relevância para as delibe- 


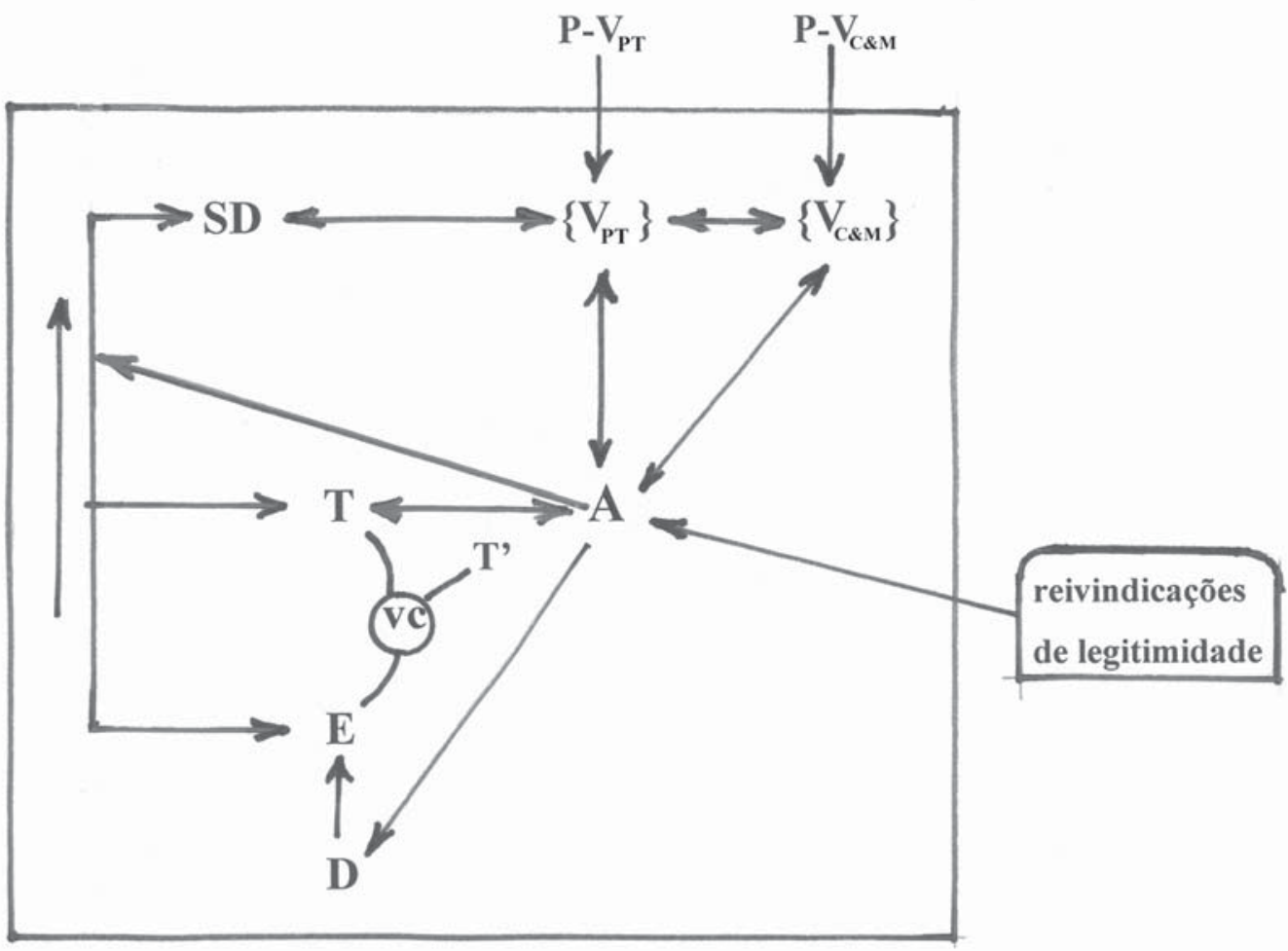

Figura 4. O circuito fechado, os pressupostos das perspectivas de valores e as reivindicações de legitimidade. Note-se que tanto os pressupostos quanto as reivindicações estão fora do circuito fechado da pesquisa conduzida segundo as perspectivas descontextualizadoras.

rações sobre a legitimidade da implementação de uma inovação e sobre a formação de políticas públicas para o uso comercial e regulamentação das inovações tecnocientíficas. Isso porque - devido às complexidades, incertezas e limites do tempo disponível para as análises de risco, e devido também à impossibilidade de antecipar todos os riscos que possam ser ocasionados pelo uso "aberto" da inovação - no tempo disponível para as deliberações anteriores à tomada de decisões sobre a implementação (ou não), não podemos conduzir a pesquisa necessária para chegar a resultados aceitos de acordo com a imparcialidade. Entretanto, a investigação empírica sistemática conduzida sob as estratégias relevantes pode levar-nos a endossar as reivindicações de legitimidade (cf. Lacey, 2011; no prelo b).

Endossar uma hipótese H (por exemplo, "não há risco") é fazer o juízo de que $\mathrm{H}$ está suficientemente bem confirmada para podermos usá-la racionalmente de modo a informar nossas ações e as políticas públicas. Quando se endossa $H$, não se afirma que $\mathrm{H}$ pertence ao corpo de conhecimento científico estabelecido. Um endossamento é um 
juízo provisório, que é indispensável na vida prática nos contextos de urgência de tomada de decisões. $\mathrm{O}$ endossamento de $\mathrm{H}$ é um resultado da investigação (conduzida sob uma estratégia apropriada $S$ ), onde a investigação realizada (na etapa $M_{2}$ de $S$ ) não é suficiente para aceitar $\mathrm{H}$ de acordo com a imparcialidade (na etapa $\mathrm{M}_{3}$ ). Trata-se de um juízo provisório que (no futuro) pode ser aceito ou rejeitado de acordo com a imparcialidade. Antes da obtenção da imparcialidade, não há razão cognitiva alguma para considerar a pesquisa concluída em um dado domínio de fenômenos (mas frequentemente uma reivindicação de legitimidade não tem interesse em pesquisa independente do contexto de deliberação sobre uma aplicação). Não respeita a imparcialidade a consideração que confunde os endossamentos com as aceitações que estão em acordo com a imparcialidade.

Quando se endossa H, afirma-se que h é suficientemente bem confirmada para justificar que agora se pode agir com base na suposição de sua verdade, isto é, que ela é suficientemente bem confirmada de modo que não é necessário levar em conta as consequências que se seguiriam, se ela viesse a informar ações, ainda que, na verdade, fosse falsa. Como avaliar que H é "suficientemente bem confirmada"? Não é possível dar uma resposta geral, mas somente respostas caso-a-caso que levam em consideração a seriedade ética do dano (ou malefício) que se arrisca: quanto maior a seriedade ética do dano arriscado, maior deve ser a probabilidade de que o dano realmente não ocorrerá. O endossamento de H, portanto, é influenciado por juízos sobre a seriedade ética dos danos potenciais, que variam segundo as perspectivas de valor sustentadas. Embora haja por causa disso um tipo de relatividade pertinente aos endossamentos, as reivindicações endossadas não são simplesmente assuntos de opinião ou de conveniência. Dados empíricos (obtidos em $\mathrm{M}_{2}$ de $\mathrm{S}$ ) constituem parte de sua base racional. Os valores éticos e sociais não fazem parte da evidência para um endossamento e não funcionam ao lado dos valores cognitivos. Seu papel é o de fazer juízos sobre a suficiência da evidência disponível para legitimar inovações informadas pela reivindicação endossada (cf. Lacey, 2011; no prelo b).

\section{Conclusão}

O M-CV, ao incorporar o pluralismo estratégico e atribuir papéis diferentes para os valores nas diferentes etapas da pesquisa científica, ilumina o papel representado pelos endossamentos na produção de juízos de legitimidade. Novamente, é importante considerar que as SDs não são apropriadas para investigar as reivindicações de legitimidade. Assim, onde a pesquisa é conduzida de acordo com $\left[\mathrm{PS}_{2}\right]$, na qual essas reivindicações não são investigadas sob as SCs, é provável que haja uma tendência a tratar os 
endossamentos como reivindicações aceitas de acordo com a imparcialidade. O M-CV permite sua investigação e mostra que na etapa $\mathrm{M}_{5}$ da pesquisa conduzida sob as SDs está também em jogo outra etapa que depende de pesquisa conduzida em $\mathrm{M}_{2}$ sob algumas SCs.

O M-CV é compatível com o funcionamento como ideais reguladores tanto da abrangência como da neutralidade, além de permitir uma defesa forte da imparcialidade. Mostra também que existe uma interdependência entre as estratégias que se manifestam claramente nas etapas $\mathrm{M}_{1}$ e $\mathrm{M}_{5}$, de modo que as estratégias se complementam entre si. Desse modo, ao identificar os pontos de contato entre as estratégias, o modelo mostra como e onde um circuito fechado (ver a figura 4) abre-se ao contato com as etapas de outros circuitos.

Agradecimentos. Os autores agradecem o financiamento da Fapesp recebido pelo Projeto Temático 2011/51614,-3: "Gênese e significado da tecnociência: das relações entre ciência, tecnologia e sociedade", do qual este artigo é um dos resultados.

Hugh LACEY

Swarthmore College, USA. Instituto de Estudos Avançados, Universidade de São Paulo, Brasil. hlaceyı@swarthmore.edu

\section{Pablo Rubén Mariconda}

Departamento de Filosofia,

Faculdade de Filosofia, Letras e Ciências Humanas, Instituto de Estudos Avançados, Universidade de São Paulo, Brasil. ariconda@usp.br

The model of interactions 


\section{ABSTRACT}

In this article, we offer standardized versions of the principal ideas of the model of the interactions among scientific activities and values that has been proposed in recent years within Scientiae Studia. The model deals with the various roles played by values - ethical, social, political, cognitive (epistemic), religious, etc-in scientific activities, and with their impact on the viability of the ideals (impartiality, comprehensiveness, neutrality, autonomy) of the tradition of modern science.

KeYwords • Scientific activity. Values. Impartiality. Comprehensiveness. Neutrality. Autonomy. Epistemology. Ethics. Scientific politics.

\section{REFERÊNGIAS BIBLIOGRÁFIGAS}

LACEY, H. Is science value free? Values and scientific understanding. London: Routledge, 1999.

A controvérsia sobre os transgênicos: questões científicas e éticas. São Paulo: Editora Idéias e Letras, 2006.

Valores e atividade científica 1. São Paulo: Associação Filosófica Scientiae Studia/Editora 34, 2008.

O lugar da ciência no mundo dos valores e da experiência humana. Scientiae Studia, 7, 4, p. 681701,2009 .

. Valores e atividade científica 2. São Paulo: Associação Filosófica Scientiae Studia/Editora 34, 2010. . A imparcialidade e as responsabilidades dos cientistas. Scientiae Studia, 9, 3, p. 487-500, 2011.

. Tecnociência comercialmente orientada ou investigação multiestratégica. Scientiae Studia, 12, 4, p. $669-95,2014$.

. A agroecologia: uma ilustração da fecundidade da pesquisa multiestratégica. Estudos Avançados, 29, 83, 2015. No prelo a.

. "Holding" and "endorsing" claims in the course of scientific activities. Studies in History and Philosophy of Science. No prelo b.

LAGeY, H. \& Mariconda, P. R. The eagle and the starlings: Galileo's argument for the autonomy of science - how pertinent is it today? Studies in the History and Philosophy of Science, 4,3, 1, p. 122-31, 2012.

Mariconda, P. R. Technological risks, transgenic agriculture and alternatives. Scientiae Studia, 12, special issue, p. 75-104, 2014.

Oliveira, M. B. Formas de autonomia da ciência. Scientiae Studia, 9, 3, p. 527-61, 2011.

RAmos, M. DE C. Aideia de racionalidade subjacente ao modelo das interações entre a ciência e os valores: florescimento cognitivo, humano e da vida. Scientiae Studia, 12, 4, p. 711-26, 2014.

SAGrini, M. Mundo da vida e racionalidade científica. Scientiae Studia, 12, 4, p. 679-710, 2014.

\section{SIGLAS USADAS NA APRESENTAÇÃO DO M- GV}

A o ideal da abrangência

$\mathrm{AE}$ agroecologia

D um domínio de fenômenos

EPILs as estruturas subjacentes aos fenômenos, os processos e interações de seus componentes, e as leis que os governam 
I o ideal da imparcialidade

$\mathrm{M}_{1}-\mathrm{M}_{5}$ os cinco momentos (etapas) das atividades científicas

M-CV o modelo da interação entre as atividades científicas e os valores

$\mathrm{N}$ o ideal da neutralidade

P-MS pesquisa multiestratégica - pesquisa que incorpora $\left[\mathrm{PS}_{1}\right]$ e responde aos ideais de $\mathrm{A}$ e de $\mathrm{N}$

$\mathrm{P}-\left\{\mathrm{V}_{\mathrm{C} \& \mathrm{M}}\right\}$ pressupostos de $\left\{\mathrm{V}_{\mathrm{C} \& \mathrm{M}}\right\}$

$\mathrm{P}-\left\{\mathrm{V}_{\mathrm{PT}}\right\}$ pressupostos de $\left\{\mathrm{V}_{\mathrm{PT}}\right\}$

$\left[\mathrm{PS}_{1}\right]$ a concepção da natureza da pesquisa científica do M-CV - permite um pluralismo estratégico que envolve o uso das SCis bem como das SDs.

[PS ${ }_{2}$ a concepção da natureza da pesquisa científica que predomina na ciência moderna - envolve o uso quase exclusiva das SDs.

$\mathrm{S}$ uma estratégia - que restringe os tipos da teoria usada num projeto da pesquisa, e seleciona os tipos dos dados empíricos relevantes para a pesquisa.

$\mathrm{S}_{\mathrm{AE}}$ estratégia de pesquisa na $\mathrm{AE}$

SCs estratégias sensíveis ao contexto - estratégias não redutíveis às SDs

SDs estratégias descontextualizadoras - restringem $\mathrm{T}$ para representar as EPILs de D.

T uma teoria

$\mathrm{T}_{\mathrm{D}}$ T representa conhecimento e entendimento dos fenômenos do D

TC tecnociência comercialmente orientada - pesquisa, que incorpora $\left[\mathrm{PS}_{2}\right]$, que busca inovações tecnocientíficas que servem especialmente bem $\left\{\mathrm{V}_{\mathrm{PT}}\right\}$ e $\left\{\mathrm{V}_{\mathrm{C \& M}}\right\}$. Expressa também o que se chama comumente "tecnologia convencional".

$\{\mathrm{V}\}$ uma perspectiva de valor

$\mathrm{VC}$ valor cognitivo

$\left\{\mathrm{V}_{\mathrm{C \& M}}\right\}$ a perspectiva de valor do capital e do mercado

$\left\{\mathrm{V}_{\mathrm{PT}}\right\}$ a perspectiva de valor do progresso tecnológico

$\left\{\mathrm{V}_{\text {JSDPS }}\right\}$ a perspectiva de valor da justiça social, democracia participativa e sustentabilidade 